\title{
Timely inspection a must
}

Received (in revised form): 19th May, 2008

\section{Tom Gregory}

Tom Gregory is head of the Energy Services Department for Chiltern Dynamics, a part of Chiltern International Fire, which has over 30 years experience of both laboratory and in situ testing. Working with a team of experienced test engineers, the department specialises in thermo graphic and air permeability inspections, in response to the demands required by Part $L$ of the building regulations. Chiltern Dynamic is one of only eight companies that have dual accreditation as members of both the Air Tightness Testing and Measurement Association (ATTMA) and the United Kingdom Accreditation Service (UKAS).

Correspondence: Tom Gregory, Energy Services Department, Chiltern Dynamics, Chiltern Group, Stocking Lane, Hughenden Valley, High Wycombe, Bucks HP14 4ND, UK; Tel: + 44 (0) 1494 569800; Fax: + 44 (0) 1494564895 ; E-mail: airtight@chilterndynamics.co.uk

\begin{abstract}
Part $L$ of the Building Regulations requires a level of air permeability in new buildings, as part of the measures needed to reduce heat losses. This requires testing to establish the volume of air escaping through gaps, cracks and holes, to ensure that the standard of less than $10 \mathrm{~m}^{3}$ of air per hour for every square metre of the envelope is not being exceeded. This paper describes the most significant air paths and some of the design and detailing measures that can reduce air losses. Services are cited as a major source of air leakage, and the paper identifies the responsibility of services engineers in maintaining a continuous barrier to air leakage. A dual process of education of services tradesmen and timely inspection is proposed to ensure that air tightness levels are not compromised. The period just prior to handover of the property is seen as the optimum moment for undertaking air tightness tests.

Journal of Building Appraisal (2008) 4, 37-40. doi:10.1057/jba.2008.17
\end{abstract}

\section{Keywords:}

air permeability, continuous air barrier, heat losses, air leakage pathways

Approved Document L - Conservation of Fuel and Power of the England and Wales Building Regulations requires new dwellings, new buildings other than dwellings and 'large' extensions to non-dwellings to achieve reasonable levels of air permeability as part of minimising heat loss through the building fabric. Performance is proven through on-site pressure testing.

The test measures the amount of heated/cooled air escaping through gaps, cracks and holes. Buildings must demonstrate that they are not losing more than $10 \mathrm{~m}^{3}$ of air, every hour, across every square metre of the 'envelope' when pressurised to $50 \mathrm{~Pa}$.

Identifying, creating and maintaining a continuous barrier to air leakage is the shared responsibility of the designer, building contractor and often numerous sub-contractors.

Communication is vital - if plumbers, electricians and other tradesmen are not aware of the air barrier, they cannot maintain it. Timely inspection is also important where critical work may be hidden by panels, suspended ceilings, raised floors or boxing.

Details have been developed to support Part L1A. They effectively provide good practice for key details with respect to insulation and air permeability. The 'Accredited Construction Details' have the added benefit of potentially reducing the number of units tested on a housing development and improving SAP ratings based on insulation. They are freely available from the Planning Portal website (see below). 
The diversity of building design and construction means that no list of potential air leakage paths can be exhaustive, but assuming that the products and materials that make up the air barrier are relatively impermeable, problems are most likely to occur in two main categories: at junctions between external/party walls (Figure 1), floors and ceilings/ roofs; and around penetrations through these elements.

The most significant air leakage paths are likely to be where a small gap is repeated along a length of the building. In many buildings, the air barrier is the internal finish or external construction, but there may be complications. Voids and risers for services can act as 'chimneys' if air can enter them and they are not sealed top and bottom (Figure 2). Ventilated, unconditioned spaces such as plant rooms, garages and lofts can cause air leakage unless their internal walls are treated as if they were external.

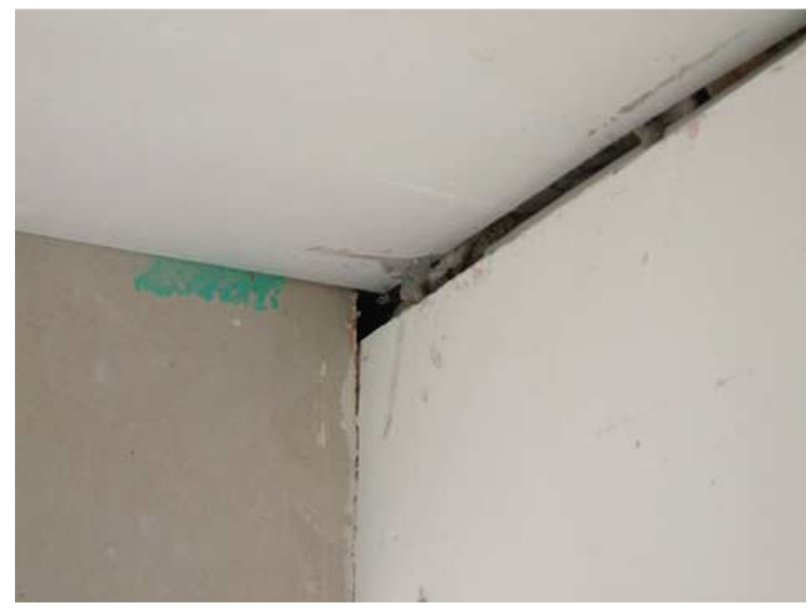

Figure I: Example of problem areas

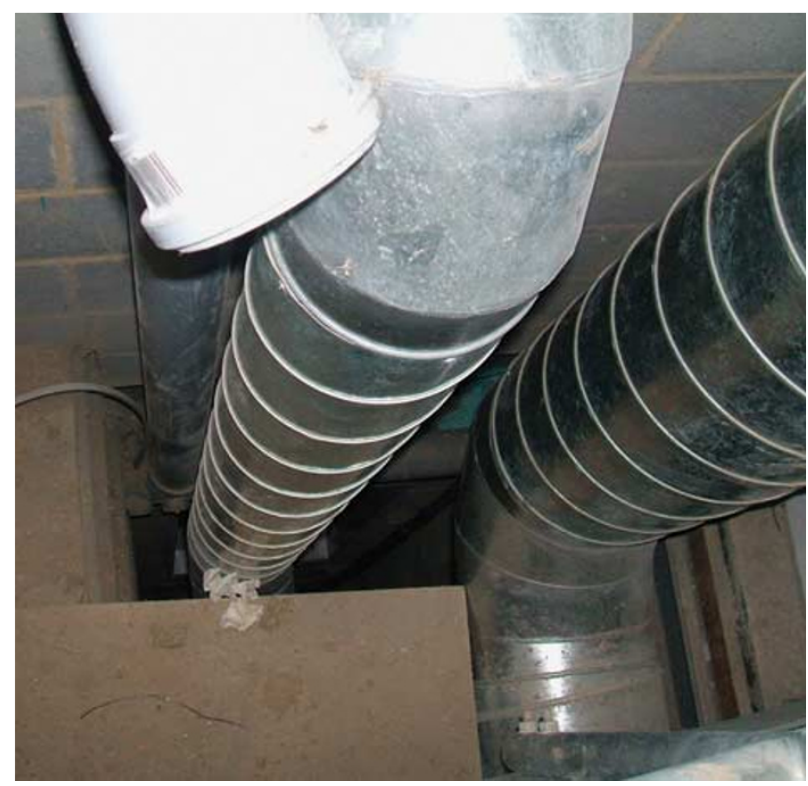

Figure 2: Service risers to ventilated plant room 
Detailing, finishing and sealing between the walls, floors and ceilings/roof that make up the air barrier are critical to achieving air tightness (Figure 3). For example, in industrial units it is likely that the air barrier will be formed by the internal surface of the cladding system. We have seen problems along eaves details, where the gap between the roof and the wall has not been sealed at all or it has been sealed with mineral wool which is air permeable.

High-quality windows, professionally installed, should perform well, but we do see poor/defective products that do not close sufficiently to compress the weather seals. Problems also occur with doors when thresholds are not fitted before the test is conducted.

Other products that can cause air leakage include:

- Trickle vents, which are closed but not sealed during testing. It is important they create a good seal and are not damaged, distorted or dirty.

- Loft hatches - in our experience, many of the plastic hatches used for domestic applications may distort or be ill-fitting (Figure 4).

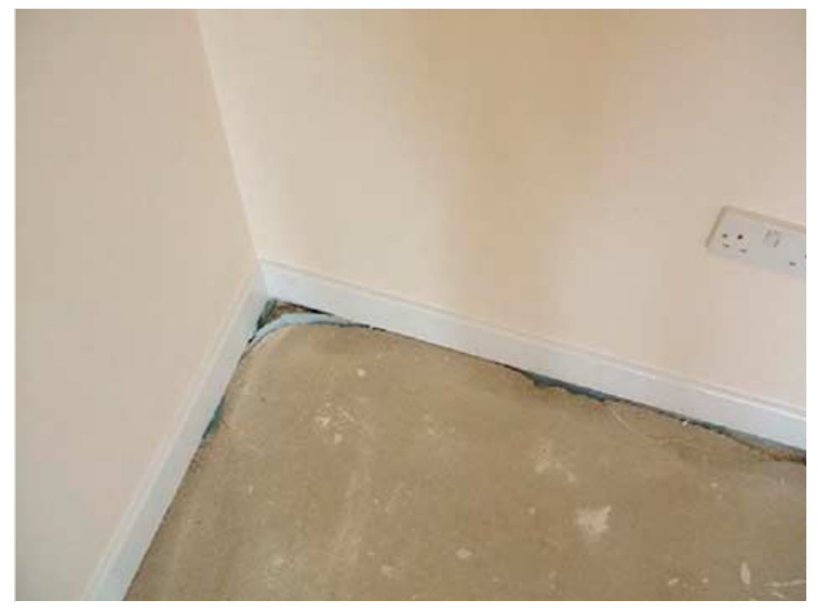

Figure 3: Wall/floor junction

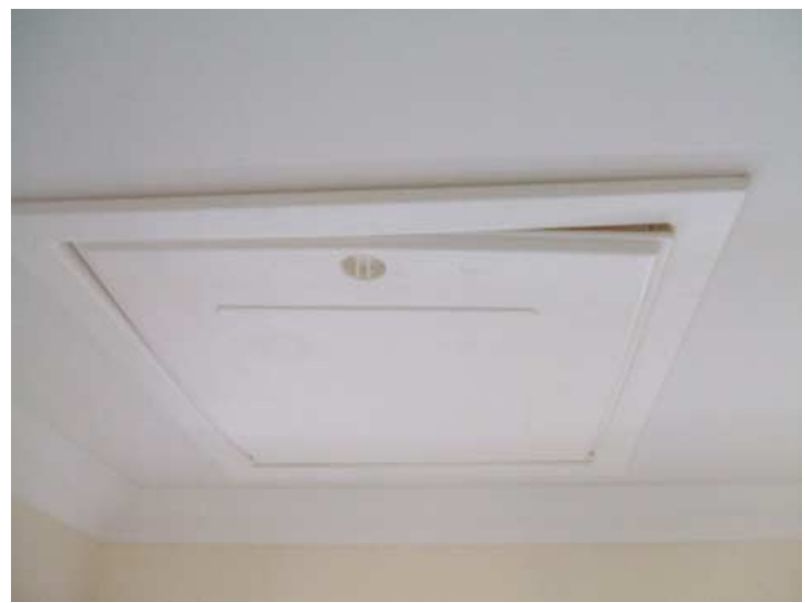

Figure 4: Loft hatch 
- Industrial doors such as roller shutters with brush seals, for example, are likely to leak along the edges and at the top.

Particular care needs to be taken with all services. Heating, water and waste pipes may allow air to leak around them if not tightly sealed. Likewise, where joists and beams penetrate the air barrier, they will require careful sealing — this may be forgotten if they are 'hidden' above suspended ceilings.

From a Building Control perspective the test could be conducted when all the penetrations have been made. To achieve the best result, the test should, however, be carried out when the building is 'complete', typically in the last week or two of the project, when all works that impact the air permeability have been finalised.

\section{References}

Accredited Construction Details for Part L, http://www.planningportal.gov.uk/england/professionals/en/1115314255826. html.

Two FREE Technical Information Sheets are available: TI-0808 - Air Tightness Testing, covering the regulatory requirements and TI-0809 Achieving Air Tightness in Buildings. 